\title{
The Influence of Performance on Action-Effect Integration in Sense of Agency
}

\author{
Wen Wen, Atsushi Yamashita, Hajime Asama \\ Department of Precision Engineering, University of Tokyo, 7-3-1 Hongo, Bunkyo-ku, \\ Tokyo 113-8656, Japan
}

Corresponding author:

Wen Wen

Department of Precision Engineering, University of Tokyo, 7-3-1 Hongo, Bunkyo-ku,

Tokyo 113-8656, Japan; Email: wen@ robot.t.u-tokyo.ac.jp; Telephone:

+81-3-5841-6486; Fax: +81-3-5841-8547

Co-authors:

Atsushi Yamashita, Email: yamashita@ robot.t.u-tokyo.ac.jp

Hajime Asama, Email: asama@ robot.t.u-tokyo.ac.jp 


\begin{abstract}
Sense of agency refers to the subjective feeling of being able to control an outcome through one's own actions or will. Prior studies have shown that both sensory processing (e.g., comparisons between sensory feedbacks and predictions basing on one's motor intentions) and high-level cognitive/constructive processes (e.g., inferences based on one's performance or the consequences of one's actions) contribute to judgments of sense of agency. However, it remains unclear how these two types of processes interact, which is important for clarifying the mechanisms underlying sense of agency. Thus, we examined whether performance-based inferences influence action-effect integration in sense of agency using a delay detection paradigm in two experiments. In both experiments, participants pressed left and right arrow keys to control the direction in which a moving dot was travelling. The dot's response delay was manipulated randomly on 7 levels $(0-480 \mathrm{~ms})$ between the trials; for each trial, participants were asked to judge whether the dot response was delayed and to rate their level of agency over the dot. In Experiment 1, participants tried to direct the dot to reach a destination on the screen as quickly as possible. Furthermore, the computer assisted participants by ignoring erroneous commands for half of the trials (assisted condition), while in the other half, all of the participants' commands were executed (self-control
\end{abstract}


condition). In Experiment 2, participants directed the dot as they pleased (without a specific goal), but, in half of the trials, the computer randomly ignored $32 \%$ of their commands (disturbed condition) rather than assisted them. The results from the two experiments showed that performance enhanced action-effect integration. Specifically, when task performance was improved through the computer's assistance in Experiment 1, delay detection was reduced in the 480-ms delay condition, despite the fact that $32 \%$ of participants' commands were ignored. Conversely, when no feedback on task performance was given (as in Experiment 2), the participants reported greater delay when some of their commands were randomly ignored. Furthermore, the results of a logistic regression analysis showed that the threshold of delay detection was greater in the assisted condition than in the self-control condition in Experiment 1, which suggests a wider time window for action-effect integration. A multivariate analysis also revealed that assistance was related to reduced delay detection via task performance, while reduced delay detection was directly correlated with a better sense of agency. These results indicate an association between the implicit and explicit aspects of sense of agency.

Keywords: sense of agency, performance, sensory, comparator model, intentional binding 


\section{Introduction}

In daily life, we typically experience a feeling of control over our own actions and the resulting external outcomes. This subjective feeling of control is called the sense of agency (Gallagher, 2000). The sense of agency is a fundamental component of how people cognitively distinguish the self and other. The mechanism of sense of agency, along with its dynamics in both normal individuals and patients with mental disorders, has received much attention from researchers in multiple fields, such as psychology, neuroscience, psychiatry, and engineering.

Both low- and high-level processes are thought to contribute to sense of agency. Low-level processes refer to sensory processes, and are highlighted in the comparator model of sense of agency. This model proposes that sense of agency emerges from matches between individuals' predictions based on efference copies of motor signals and actual sensory feedback (Blakemore, Frith, \& Wolpert, 1999; Blakemore, Wolpert, \& Frith, 1998, 2002; Frith, Blakemore, \& Wolpert, 2000; Wolpert \& Ghahramani, 2000). In other words, if a person's sensory feedback does not match this prediction or is absent entirely, that person's sense of agency would diminish. This sensory account has been used to explain disorders in sense of agency. For example, schizophrenia patients often show aberrant feelings of agency (Franck et al., 2001; Haggard, Martin, 
Taylor-Clarke, Jeannerod, \& Franck, 2003; Koreki et al., 2015; Maeda et al., 2012),

which are thought to be related to imprecise predictions about the sensory consequences of actions (Knoblich, Stottmeister, \& Kircher, 2004; Lindner, Thier, Kircher, Haarmeier, \& Leube, 2005; Synofzik, Thier, Leube, Schlotterbeck, \& Lindner, 2010).

High-level/reconstructive processes also appear to play important roles in individuals' sense of agency (Synofzik, Vosgerau, \& Newen, 2008). For example, Wegner, Sparrow, and Winerman (2004) reported that people feel an illusory sense of agency for another person's hands when they hear instructions for that person's movements in advance. Wegner (2003) suggested that the experience of agency could be based on postdictive inference. Furthermore, recent studies have shown that participants report a strong sense of agency when they obtain good task performance, even when the enhanced performance was clearly the result of external factors (Metcalfe, Eich, \& Miele, 2013; Metcalfe \& Greene, 2007; Sato \& Yasuda, 2005; Wen, Yamashita, \& Asama, 2015a) or their actual control over the effects was disturbed (Wen, Yamashita, \& Asama, 2015b). Wen, Yamashita, and Asama (2015a) proposed that individuals' intent to achieve a goal plays an important role in forming a sense of agency. If an individual's actions result in a goal of theirs being achieved, they would feel a strong sense of agency over the effects of their actions; however, if the 
individual's actions cause them to fail to achieve this goal, their sense of agency would be diminished.

Moreover, prior research has reported that when sensory processes become unreliable, high-level processes based on performance (i.e., a performance-based inference) take over in judgments of sense of agency (Wen et al., 2015b). This phenomenon can be explained by cue integration theory (Moore \& Fletcher, 2012), which proposes that both internal and external cues contribute to a sense of agency, and that these cues are integrated based on a Bayesian principle. Generally, internal cues based on sensory processes in normal individuals and situations are the most reliable, and thus are the strongest contributors to a sense of agency. However, when the reliability of these cues decreases, external cues such as performance-based inferences take a more dominant role (Moore \& Haggard, 2008; Wen et al., 2015b).

In summary, both sensory (i.e., low-level) processes and high-level processes appear to contribute to a sense of agency, and are thought to be integrated according to a Bayesian principle (Moore \& Fletcher, 2012; Synofzik, Vosgerau, \& Voss, 2013). However, how these processes interact remains unclear; understanding their interaction is important for clarifying the precise mechanism of the sense of agency. One particular line of research concerning sensory processes (i.e., action-effect integration) relates to 
the "intentional binding effect." This phenomenon has been widely observed at the sensory level in agency tasks (Haggard, Clark, \& Kalogeras, 2002), and refers to a subjective compression of the interval between one's intentional action and its effect (Haggard et al., 2002). It is considered to reflect an implicit aspect of sense of agency (Moore, Middleton, Haggard, \& Fletcher, 2012). More specifically, in tasks involving a sense of agency, the perceived interval between an action and its effect is shortened. The intentional binding effect might be influenced by both action-related factors, such as intention (e.g., Berberian, Sarrazin, Le Blaye, \& Haggard, 2012; Vinding, Pedersen, \& Overgaard, 2013), effort (Demanet, Muhle-Karbe, Lynn, Blotenberg, \& Brass, 2013; Howard, Edwards, \& Bayliss, 2016), and action selection (Barlas \& Obhi, 2013), and effect-related factors, such as the attentional focus on the effect (Haggard \& Cole, 2007) and the priming of the effect (Moore, Wegner, \& Haggard, 2009). Recent studies have also shown that the intentional binding effect is influenced by negative emotions (e.g., Yoshie \& Haggard, 2013), monetary outcomes (Takahata et al., 2012), beliefs (Desantis, Roussel, \& Waszak, 2011), moral contexts, and moderation of outcomes (Moretto, Walsh, \& Haggard, 2011). These findings suggest the possible influence of high-level processes on the sensory processes underlying the sense of agency. However, there are currently no studies exploring the possible interaction effects of high- and low-level 
factors on sense of agency.

To examine these issues, we used a delay detection paradigm, whereby

participants continuously press keys to trigger external effects and receive feedback on their performance related to these effects. The subjective delay between participants' actions and the effects of those actions reflect a sensory action-effect integration, which helps in forming an implicit sense of agency (Bednark, Poonian, Palghat, McFadyen, \& Cunnington, 2015; Moore et al., 2012). For this study, we created an assisted controlling mode for the computer program running the delay detection task, which was designed to improve participants' task performance by ignoring erroneous actions (Wen et al., 2015b). We then examined how this assistance influenced both delay detection and the sense of agency (Experiment 1) by comparing these two constructs between this assistance condition and a condition wherein a percentage of participants' commands were randomly ignored (Experiment 2). We hypothesized that improving participants' task performance would reduce delay detection, especially when the delay is relatively long. Additionally, we hypothesized that performance-based inferences would have more weight than would sensory processes in determining the sense of agency (Wen et al., 2015b). We also examined participants' explicitly rated agency to clarify how the integration of multiple cues from different levels of processing influences sense of 
agency.

\section{Methods}

\subsection{Participants}

In Experiments 1 and 2, the participants were 17 (two females, three

left-handed, mean age 24.8, range 22-31) and 16 students (two females, all right-handed, mean age 24.8 , range $22-32$ ), respectively, all of whom had normal or corrected-to-normal visual acuity. The results from one participant in Experiment 1 were excluded from the analysis because they largely failed to detect delays (giving only 8 delay reports out of 140 trials). The experiments were conducted with the approval of the ethics committee of the Faculty of Engineering at the University of Tokyo, and written informed consent was obtained from all participants.

\subsection{Stimuli and Task}

Both experiments used the same stimuli and tasks. The experimental task was a modified version of the delay detection task used in a previous study (Wen et al., 2015b). In each trial, a white cross was first shown at the center of a $597 \mathrm{~mm} \times 336 \mathrm{~mm}$ (width $\times$ height) black screen for $500 \mathrm{~ms}$, after which it was replaced by a 6-mm white dot (Figure 1). The dot moved at a frequency of $124 \mathrm{~mm} / \mathrm{s}$ in a randomly determined direction that was never towards the destination. The destination was a 31-mm black 
square with a white border, which appeared at one of the four corners of the screen after the cross disappeared. It remained on the screen until the dot arrived in the square. The direction of the dot did not change until the dot reached the border of the screen or participants pressed the left or right arrow keys. The dot rebounded when it arrived at the border. Participants were told to press the left and right arrow keys on a keyboard, using the index and middle fingers of their dominant hand, to change the direction in which the dot was travelling. Their goal was to direct the dot into the square as quickly as possible. The dot's direction shifted $20^{\circ}$ clockwise with each right key press and $20^{\circ}$ counterclockwise with each left key press. If participants held down either key, the dot would change direction at a frequency of $190 \%$ s in the first second and $330 \%$ s thereafter. Participants were told to hold the keys down if they wanted the dot to spin, and to briefly press the keys if they wanted to make precise adjustments. 


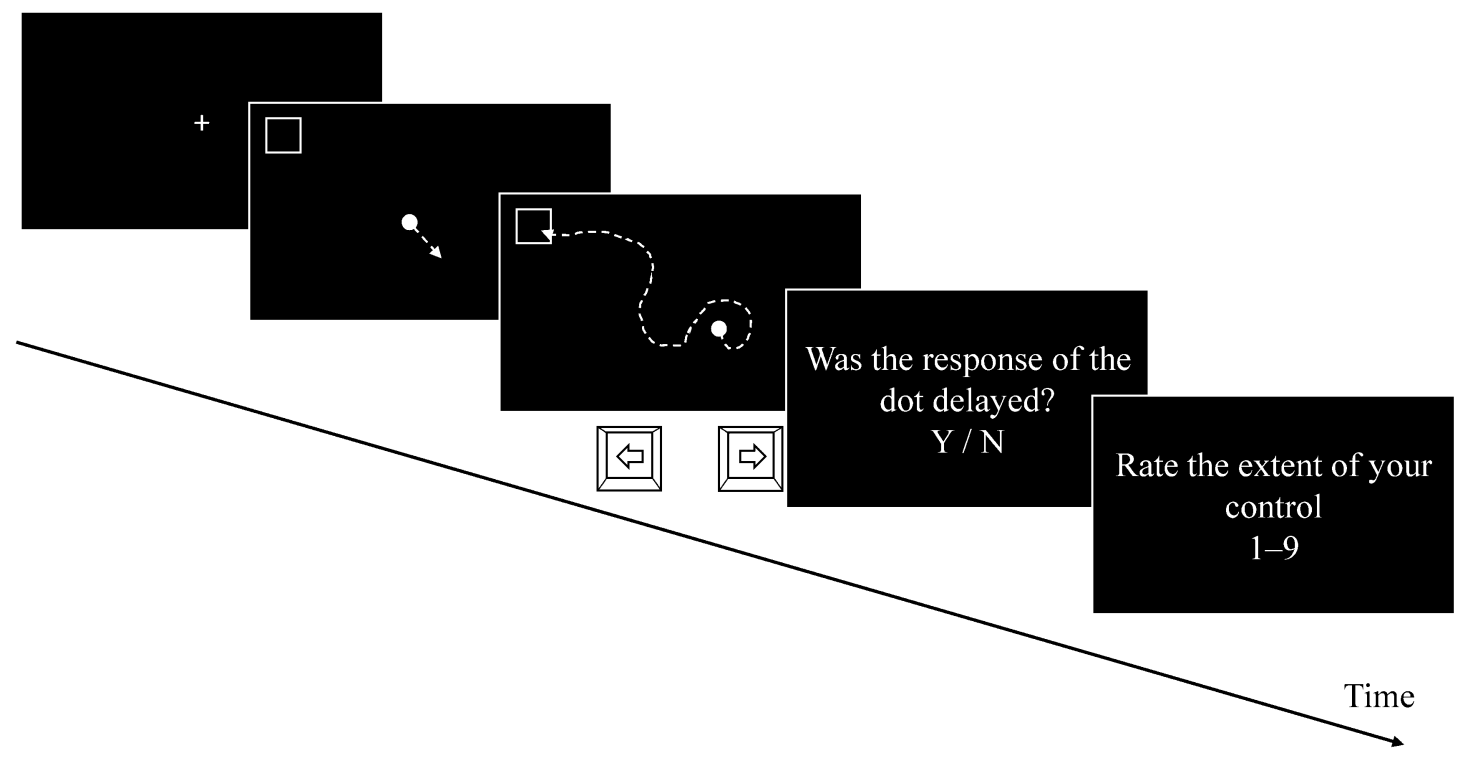

Figure 1. The flow of each trial in the experimental task. Participants were instructed to direct a moving dot into its destination as quickly as possible by pressing the left and right arrow keys, which changed the direction in which the dot travelled. After the dot had reached the destination, participants made a two-alternative forced choice regarding whether the dot's response to their key press had been delayed, and then rated their sense of control over the direction in which the dot travelled.

After reaching the destination, the dot stopped moving and disappeared along with the square after $200 \mathrm{~ms}$. Then, participants were asked to indicate whether they felt that the dot's response to each of their key presses had been delayed by using the computer mouse to click one of two radio buttons on the screen. They followed this by rating the extent to which they felt that their key presses had caused the dot to change direction on a 9 -point scale $(1=$ not at all to $9=$ a lot $)$ by clicking one of nine radio 
buttons on the screen. Participants were informed of the within-trial consistency in delays. They were told that the delay detection and agency ratings referred to different aspects of the task. Specifically, they were first told that the dot might sometimes fail completely to respond to their key press, whereas on other occasions, it might respond only after a certain delay. Whenever they detected any delay in response, they should press the "delayed" button. Similarly, whenever they realized that some of their key presses did not work, they should rate their feeling of agency with a smaller number. In contrast, if the dot responded to all their key presses, even after an obvious delay, they should rate their agency with a larger number.

There were seven possible intervals $(0,80,160,240,320,400$, and $480 \mathrm{~ms})$ between the participants' key press and the dot's response. The delay was consistent within each trial but varied randomly between the trials.

\subsection{Experiment 1}

Participants were instructed to direct the dot to the destination on the screen as quickly as possible in Experiment 1. There were two controlling mode conditions in this experiment: self-control and assisted. In the self-control condition, all of the participants' commands were executed. In the assisted condition, when the angle between the direction of the dot and the target location was less than $90^{\circ}$, commands that caused the 
dot to move away from the destination were ignored (Wen et al., 2015b). This assistance would ignore a percentage of the participants' commands, thereby resulting in a disturbance in their sensory processes (i.e., mismatches of motor commands and actual sensory feedback). However, it would also enhance task performance (i.e., earlier arrival at the destination). There were 140 trials in Experiment 1, comprising 10 trials of each delay duration $(0,80,160,240,320,400$, and $480 \mathrm{~ms})$ for each controlling mode condition. The trials were presented in a random order.

\subsection{Experiment 2}

In Experiment 2, the square (i.e., the destination) was not presented on the screen. Instead, participants were instructed to control the direction of the dot as they pleased for a limited duration to confirm whether the dot showed a delay in response and whether their commands were effective. The duration of dot controlling was 8300 ms, which was the mean time taken for the dot to reach its destination in Experiment 1 (see section 3.3 for details). There were two controlling mode conditions in Experiment 2: self-control and disturbed. The self-control condition was the same as that in Experiment 1, while in the disturbed condition, participants' commands had a $32 \%$ probability of being ignored. The probability of commands being ignored was based on the average proportion of ignored key presses in Experiment 1 (see section 3.4). There 
were also 140 trials in Experiment 2, comprising 10 trials in each delay duration $(0,80$, 160, 240, 320, 400, and $480 \mathrm{~ms}$ ) for each controlling mode condition. As in Experiment 1 , the trials were presented in a random order.

\subsection{Procedure}

The procedures and instructions of Experiments 1 and 2 were identical.

Participants were tested individually in a quiet room, seated on a chair that kept their eyes about $50 \mathrm{~cm}$ away from a 27-inch LCD monitor (resolution 1,920 × 1,080 pixels).

After receiving an explanation of the experimental task, participants performed six practice trials. They were informed that in half of these practice trials, there would be no delay in the dot's response, while in the remaining half there would be a delay of 480 ms. Participants were also told that all of their commands would be effective during the practice trials (but would occasionally be ineffective during the actual task). The order of the practice trials was randomized. Following the practice trials, each participant completed the 140 experimental trials. Participants were given a 5-min break after completing half of the trials. Upon completing all trials, participants verbally reported on whether they had noticed that the effectiveness of their commands was following any specific rule. The experiment lasted for $45 \mathrm{~min}$ on average.

\subsection{Multivariate Analysis}


To examine the relationship between delay detection and sense of agency, we performed structural equation modeling using IBM SPSS Amos 22. The model contained two independent variables - delay and assistance - and three dependent variables: delay detection rate (delayed or not delayed), task performance, and agency rating (see Figure 7 in section 3.5). Task performance was indexed as the minus value of the time taken for the dot to reach its destination, normalized within participants (by subtracting the mean and dividing the result by the standard deviation of each participant) to minimize the individual differences in motor control ability. In the model, we drew direct paths from the two independent variables to all three dependent variables, and paths from task performance and delay detection rate to sense of agency. A path from task performance to delay detection rate was also drawn. We pooled all trials from all participants for this model.

\section{Results}

\subsection{Delay Detection in Experiments 1 and 2}

The average delay detection rates (with their standard errors) in Experiments 1 and 2 are shown in Figures 2a and 2b, respectively. First, we examined the overall influence of controlling mode and delay on the results of the two experiments using $2 \times$ 7 (controlling mode $\times$ delay) repeated-measures analyses of variance (ANOVAs). In 
Experiment 1 , the main effect of delay $\left(F(6,90)=33.33, p<.001, \eta_{\mathrm{p}}{ }^{2}=0.69\right)$ and the interaction between delay and controlling mode $\left(F(6,90)=6.86, p<.001, \eta_{\mathrm{p}}{ }^{2}=0.31\right)$ were significant, but the main effect of controlling mode was nonsignificant $(F(1,15)=$ $\left.0.09, p=.764, \eta_{\mathrm{p}}{ }^{2}=0.01\right)$. Bonferroni-corrected post hoc comparisons conducted for the interaction revealed no significant differences between the self-control and assisted conditions when the delay was less than or equal to $400 \mathrm{~ms}(p=1.000,1.000,1.000$, 1.000, 1.000, and 0.211 for the 0-, 80-, 160-, 240-, 320-, and 400-ms delay conditions, respectively). However, when the delay was $480 \mathrm{~ms}$, the participants detected it significantly fewer times in the assisted condition than in the self-control condition ( $p$ $=.014)$.

In Experiment 2, the main effects of both controlling mode $(F(1,15)=39.37, p$ $\left.<.001, \eta_{\mathrm{p}}{ }^{2}=0.72\right)$ and delay $\left(F(6,90)=33.48, p<.001, \eta_{\mathrm{p}}{ }^{2}=0.69\right)$, and the interaction between controlling mode and delay $\left(F(6,90)=3.31, p=.005, \eta_{\mathrm{p}}{ }^{2}=0.18\right)$, were significant. Bonferroni-corrected post hoc comparisons conducted for the interaction revealed significant differences between the self-control and disturbed conditions when the delay was less than $320 \mathrm{~ms}$ ( $p<.001$ for the $0-, 80-, 160-$, and $240-\mathrm{ms}$ delay conditions; $p=.012, .529$, and 1.000 for the 320-, 400-, and 480-ms delay conditions). 

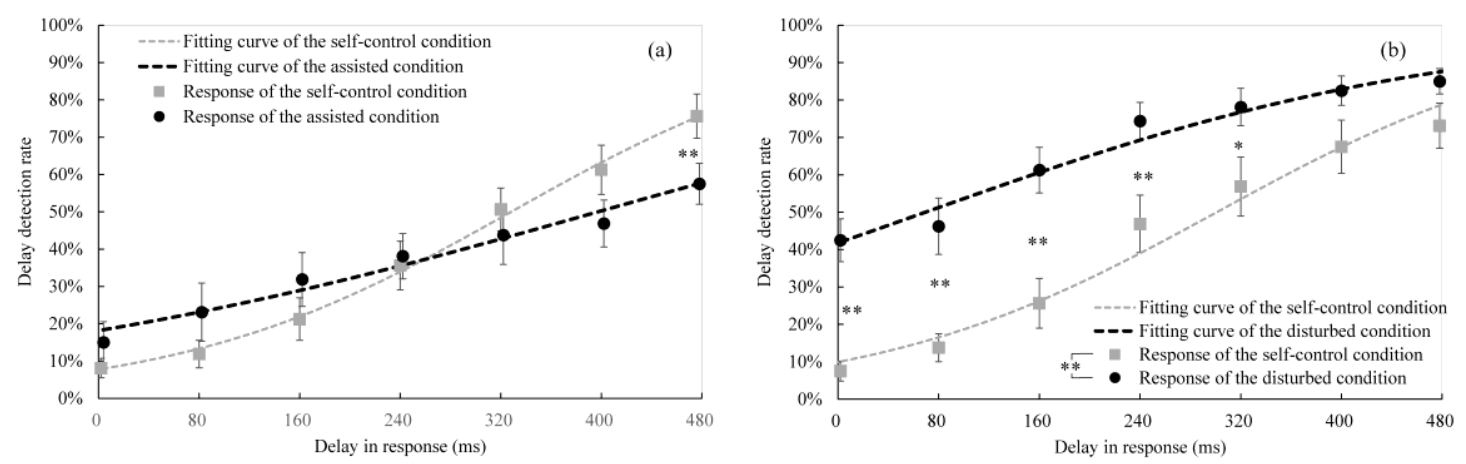

Figure 2. Mean delay detections rates in each condition in Experiment 1 (a) and

Experiment 2 (b). Error bars represent the standard errors. Broken lines represent the

logistic fitting curves for each controlling mode condition in each experiment.

Note: ${ }^{*} p<.05 ; * * p<.01$.

In addition, in order to compare participants' subjective feelings of delay

between the two experiments, we applied logistic regressions to each participant's delay

detection rates within each controlling mode. Prior studies have shown that humans'

perception of time fits well on logistic curves with time as the independent variable and

judgments of time as the dependent variable (e.g., Binetti, Lecce, \& Doricchi, 2012;

Shimada, Qi, \& Hiraki, 2010). Binomial logistic regression analyses were carried out

with MATLAB R2015a (The MathWorks, Inc.) using the generalized linear model

function in the Statistics and Machine Learning Toolbox (regression model: $\log (\pi / 1-\pi)$

$=\alpha+\beta \mathrm{x}$, where $\pi$ refers to the delay detection rates, $\mathrm{x}$ refers to the actual delay, $\alpha$ refers

to the interception, and $\beta$ refers to the slope). We focused on two parameters for the 
regression results: the slope and the threshold, with a particular emphasis on the threshold. The slope provides an estimate of the precision of the judgment of delay (Shimada et al., 2010). Precise judgments of delay refer to a high degree of correspondence between actual delay and delay detections - that is, when the actual delay increases, the number of delay detections increases rapidly, and vice versa. We employed a $50 \%$ threshold of delay detection; this threshold is the point of subjective equality, and reflects the time window required for the integration of actions and visual effects (Farrer, Valentin, \& Hupé, 2013; Shimada et al., 2010). Any results that did not significantly fit the logistic function in either controlling mode condition were excluded. This resulted in seven and five exclusions from Experiments 1 and 2, respectively. There were two reasons for the poor logistic fittings among these excluded participants: a high delay detection rate when no delay was present (the average delay detection rate of the 12 excluded participants was $44.2 \%$ for the 0 -ms delay condition), and a lack of an increase in delay detection with each increase in actual delay in both the assisted and disturbed conditions (the average slope of linear fitting was 0.0003 for the excluded participants).

The broken lines in Figure 2 show the fitting curves for the average delay detection rates in each controlling mode condition and experiment. Figure 3 shows the 
mean slopes (a) and thresholds (b) in each controlling mode condition and experiment for the significant logistic regression results. In Experiment 1, the difference in the slope between the self-control and assisted conditions was nonsignificant $(t(8)=2.03, p$ $=.077$, Cohen's $\mathrm{d}=-0.59$ ); however, the threshold of delay detection in the assisted condition was larger than was that in the self-control condition $(t(8)=-2.532, p=.035$, Cohen's $d=0.56$ ). In Experiment 2, the slope was significantly gentler in the disturbed condition than in the self-control condition $(t(10)=3.37, p=.007$, Cohen's $d=-0.77)$; however, the difference in thresholds between the two control conditions was nonsignificant $(t(10)=1.41, p=.188$, Cohen's $\mathrm{d}=-0.32)$.

In summary, the results of the logistic regression analysis showed that when a proportion of the participants' commands were randomly ignored (Experiment 2), participants exhibited less precise judgments of delay and tended to report delays more often. This might be because they occasionally perceived the ignored commands as delayed commands. In contrast, when participants' task performance was improved through the computer's assistance, their threshold of delay detection was larger compared to in the self-control condition. 

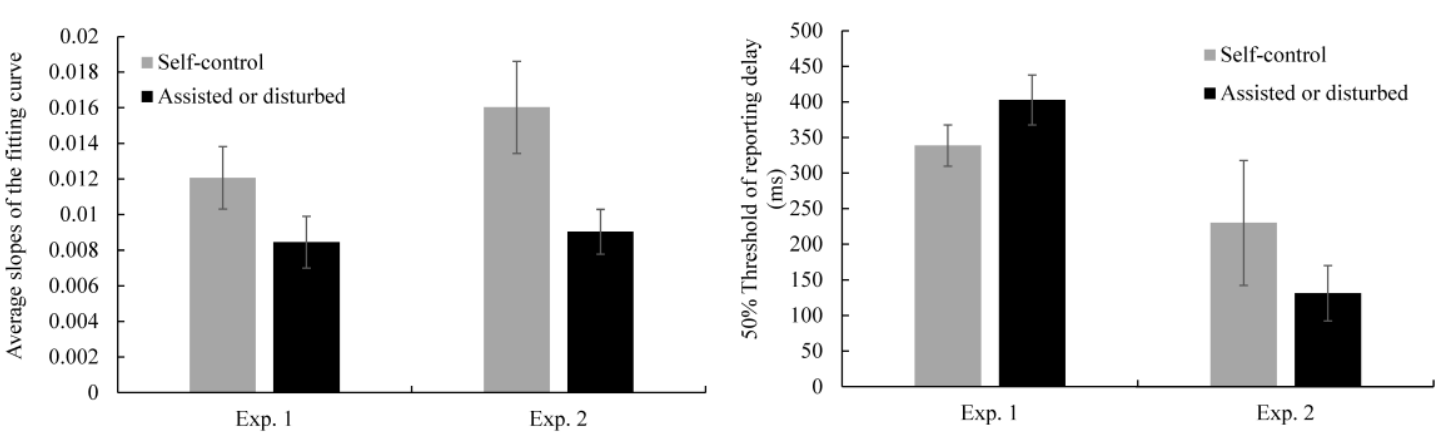

Figure 3. Mean slopes (a) and 50\% thresholds (b) of the delay detection curves for the self-control and assisted/disturbed conditions in Experiments $1(n=9)$ and $2(n=11)$.

Error bars represent the standard errors. The slope in the self-control condition of

Experiment 2 was steeper than was that in the disturbed condition. On the other hand,

the threshold of delay detection was greater in the assisted condition in Experiment 1

than in the self-control condition, but did not differ between the two conditions in

Experiment 2.

\subsection{Agency Rating}

The means and standard errors of the agency ratings in each condition of the two experiments are presented in Figure 4. We conducted $2 \times 7$ (controlling mode $\times$ delay) repeated-measures ANOVAs on the agency rating scores of the two experiments. In Experiment 1 (Figure 4a), the main effects of controlling mode $(F(1,15)=7.73, p$ $\left.=.014, \eta_{\mathrm{p}}{ }^{2}=0.34\right)$ and delay $\left(F(6,90)=23.00, p<.001, \eta_{\mathrm{p}}{ }^{2}=0.61\right)$, and the interaction between controlling mode and delay $\left(F(6,90)=5.17, p<.001, \eta_{\mathrm{p}}{ }^{2}=0.26\right)$, were all 
significant. Bonferroni-corrected post hoc comparisons of the interaction showed that the participants provided significantly lower agency ratings in the assisted condition than in the self-control condition when the dot response was delayed for $0,80,160$, or $320 \mathrm{~ms}(p<.001$ for the $0-, 80-$, and 160-ms delay conditions, respectively; $p=.003$ for the 320-ms delay condition). However, the differences between the two controlling modes were nonsignificant in the 240-, 400-, and 480-ms delay conditions $(p=.145$, 1.000 , and 1.000, respectively). Thus, participants provided lower ratings in the assisted condition than in the self-control condition even when their performance had improved. This was probably because their attention was focused on the sensory level, as they had been instructed to detect the delay. As such, the sensory disturbance might have played a dominant role in determining their sense of agency.

Regarding the agency ratings in Experiment 2 (Figure 4b), the main effects of controlling mode $\left(F(1,15)=71.65, p<.001, \eta_{\mathrm{p}}{ }^{2}=0.83\right)$ and delay $(F(6,90)=27.31, p$ $\left.<.001, \eta_{\mathrm{p}}{ }^{2}=0.65\right)$, as well as the interaction between them $(F(6,90)=4.08, p=.001$, $\eta_{\mathrm{p}}^{2}=0.21$ ), were significant. The Bonferroni-corrected post hoc comparisons of the interaction revealed that the rating scores in the disturbed condition were significantly lower than were those in the self-control condition in all delay conditions $(p<.001)$. In other words, participants noticed that a proportion of their commands did not work and 
gave lower ratings of agency in the disturbed condition.
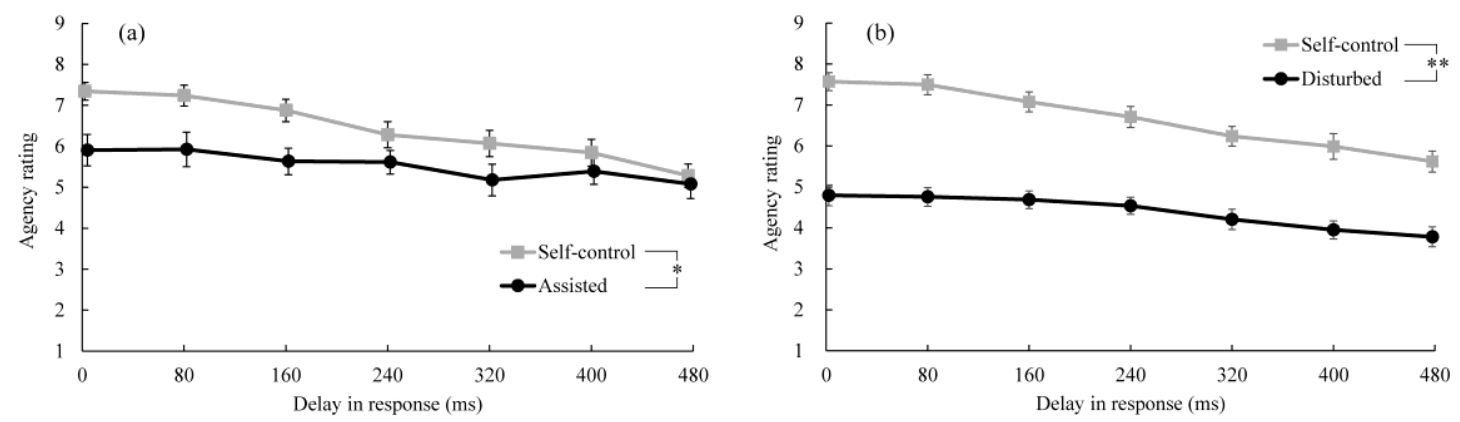

Figure 4. Mean agency rating scores in each condition in Experiment 1 (a) and

Experiment 2 (b). Error bars represent the standard errors. The agency ratings in the conditions in which a proportion of participants' commands were ignored (i.e., the assisted and disturbed conditions) were significantly lower than were those in the self-control conditions in both experiments. However, agency ratings in the two longest delay conditions did not differ between the two controlling modes in Experiment 1.

Notes: $* p<.05 ; * * p<.01$.

\subsection{Task Performance}

Because the participants were instructed to direct the dot to its destination as quickly as possible in Experiment 1, we used the time required for the dot to arrive at the destination as an index of task performance (Figure 5a). The results of task performance were used to confirm the effectiveness of the computer's assistance. A $2 \times$ 7 (controlling mode $\times$ delay) repeated-measures ANOVA revealed significant main 
effects of controlling mode $\left(F(1,15)=36.74, p<.001, \eta_{\mathrm{p}}^{2}=0.71\right)$ and delay $(F(6,90)$ $\left.=23.71, p<.001, \eta_{\mathrm{p}}{ }^{2}=0.61\right)$, and a significant interaction between controlling mode and delay $\left(F(6,90)=8.68, p<.001, \eta_{\mathrm{p}}{ }^{2}=0.37\right)$. Bonferroni-corrected post hoc comparisons of the interaction showed that the differences between the two controlling modes were nonsignificant when the delay was 0 or $80 \mathrm{~ms}(p=1.000)$. When the delay was $160,240,320,400$, or $480 \mathrm{~ms}$, however, the participants were able to direct the dot to its destination significantly earlier in the assisted condition than in the self-control condition ( $p=.001$ and .002 for the 160- and 240-ms delay conditions, respectively; $p$ $<.001$ for the 320-, 400-, and 480-ms delay conditions). Furthermore, when all of participants' commands were executed (i.e., the self-control condition), participants took significantly more time to complete the task with longer delays ( 0 vs. $160 \mathrm{~ms}, p$ $<.001 ; 80$ vs. $160 \mathrm{~ms}, p=.027 ; 160$ vs. $480 \mathrm{~ms}, p<.001 ; 240$ vs. $480 \mathrm{~ms}, p<.001 ; 320$ vs. $480 \mathrm{~ms}, p<.001 ; 400$ vs. $480 \mathrm{~ms}, p=.017)$. In contrast, when the participants were assisted by the computer (i.e., the assisted condition), only the differences between the longest delay condition (480 ms) and the two shortest delay conditions ( 0 and $80 \mathrm{~ms}$ ) were significant ( $p=.003$ and .028 , respectively). In other words, when the delay was shorter than $480 \mathrm{~ms}$ and participants had the computer's assistance, they were able to direct the dot to its destination as quickly as in the condition without delay ( $0 \mathrm{~ms})$. Thus, 
the results showed that the assistance offered by the computer did in fact improve task performance. Additionally, more than half of the participants reported having noticed the occasional ineffectiveness of their commands when the dot was travelling straight towards the destination.
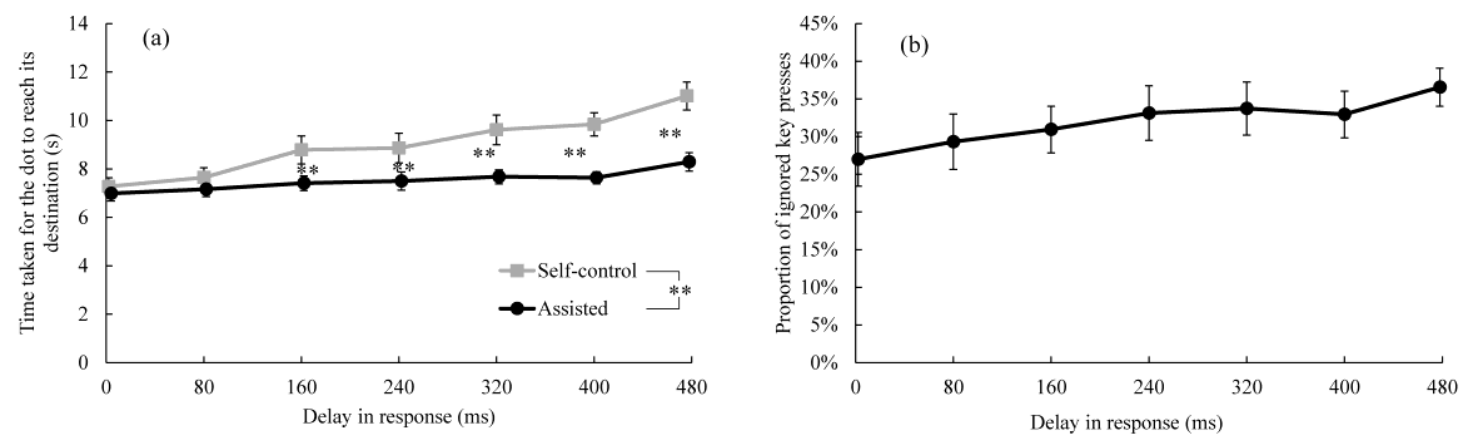

Figure 5. Mean time taken for the dot to reach in its destination in each condition (a)

and mean proportions of ignored key presses in the assisted condition (b) in Experiment 1. Error bars represent the standard errors. The assistance significantly improved task performance by ignoring the participants' erroneous commands. Note: $* * p<.01$.

To examine whether task performance was associated with delay detection, we compared task performance between the delayed and not-delayed responses in each delay condition in Experiment 1 (Figure 6). Although we already found support for this in the results of the delay detection threshold analysis, we decided to double-check it with the observed responses in the self-control condition, wherein there was no sensory 
disturbance. We used delay and response in delay detection (delayed or not-delayed) as independent variables, and time taken for the dot to reach its destination as the dependent variable. Because there were missing values for the dependent variable in many conditions (e.g., some participants made no delayed responses in conditions with very short delays), we conducted a two-factor ANOVA (between-subjects, delay $\times$ response) instead of a repeated-measures ANOVA. The main effects of response $\left(\right.$ delayed vs. not-delayed, $\left.F(1,214)=15.89, p<.001, \eta_{\mathrm{p}}{ }^{2}=0.08\right)$ and delay $(F(6,214)=$ $\left.3.63, p=.002, \eta_{\mathrm{p}}^{2}=0.10\right)$ were significant, while the interaction between response and delay was not $\left(F(6,214)=0.64, p=.695, \eta_{\mathrm{p}}^{2}=0.02\right)$. These results showed that when participants made a judgment of "delayed," they tended to show worse task performance. These results further support our hypothesis that task performance influences delay detection in an agency task.

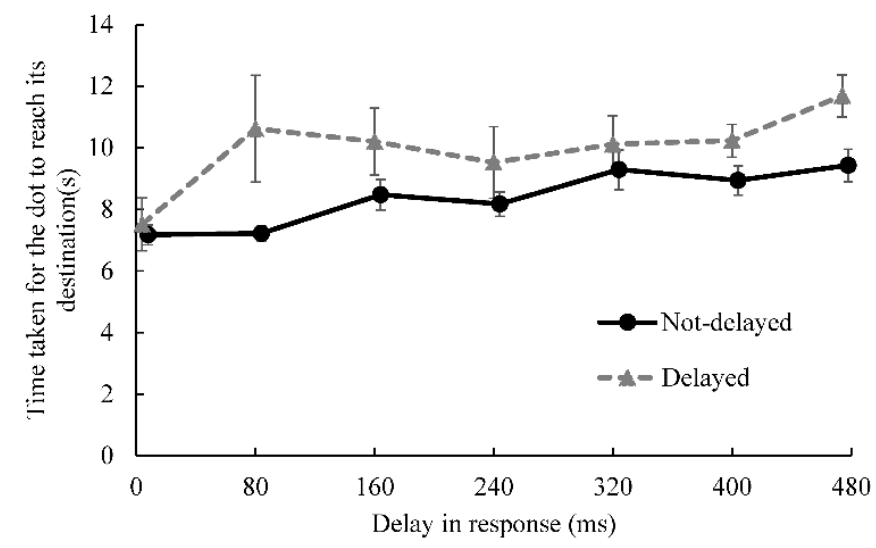

Figure 6. Mean time taken for the dot to reach in its destination in the self-control 
condition of Experiment 1, according to whether participants made judgments of not-delayed or delayed. Making a judgment of not-delayed was significantly associated with better task performance (i.e., earlier arrivals).

\subsection{Ignored Key Presses}

The proportions of ignored key presses in the assisted condition in Experiment 1 were used to estimate the extent of the sensory disturbance; these are shown in Figure $5 \mathrm{~b}$. About $32 \%$ of the participants' commands were ignored in the assisted condition on average. Thus, this $32 \%$ was used to determine the probability of commands being ignored in the disturbed condition of Experiment 2 (as mentioned in section 2.4). A one-factor (delay) repeated-measures ANOVA showed that the main effect of delay was significant $\left(F(6,90)=3.48, p=.004, \eta_{\mathrm{p}}{ }^{2}=0.19\right)$. There was a tendency for more key presses to be ignored by the computer in the assisted condition with longer delays than with shorter delays. However, Bonferroni-corrected post hoc comparisons did not reveal any significant differences in the proportion of ignored key presses between the delay conditions, except for a marginally significant difference between the 0 - and 480-ms delays $(p=.058)$. The participants made $18.46(S D=4.95)$ and $37.46(S D=8.21)$ key presses per trial in Experiments 1 and 2, respectively. The difference between the two experiments was significant $(t(30)=-7.93, p=.007$, Cohen's $d=-2.80)$. This was 
probably because the participants in Experiment 1 intentionally and carefully chose their key presses to help achieve the task goal, whereas participants in Experiment 2 just followed the instruction to repetitiously press as many keys as possible.

\subsection{Multivariate Analysis}

Delay detection reflects action-effect integration, which is associated with an implicit sense of agency. However, the above results indicated that action-effect integration improved (i.e., led to lower delay detection rates) when participants were given assistance, whereas the sense of agency was impaired by this assistance. This suggests a dissociation between action-effect integration and sense of agency. In order to delineate the complex interactions between the different factors, and to examine whether less delay detection is associated with better or worse sense of agency, we conducted structural equation modeling for the results of Experiment 1.

The standardized coefficients for all paths are depicted in Figure 7.

Non-significant paths are shown as broken lines and significant paths as solid ones. The model fit the data very well $(\mathrm{CMIN} / \mathrm{df}=.000, \mathrm{GFI}=1.000)$. This provides an overall picture of how assistance influences delay detection and sense of agency, and how delay detection and task performance contribute to sense of agency. First, assistance led to decreased delay detection via improvement of task performance. Second, assistance had 
a direct negative effect on sense of agency, likely because assistance from the computer caused a large number of commands to be ignored. However, the indirect paths between assistance and sense of agency via task performance and delay detection were positive, and the coefficient was smaller than for the direct path. Finally, and most importantly, less delay detection was strongly associated with a better sense of agency. In other words, despite finding less delay detection and a lower sense of agency in the assisted condition than in the self-control condition, the action-effect integration was not actually dissociated from the judgment of agency; in fact, they were strongly associated.

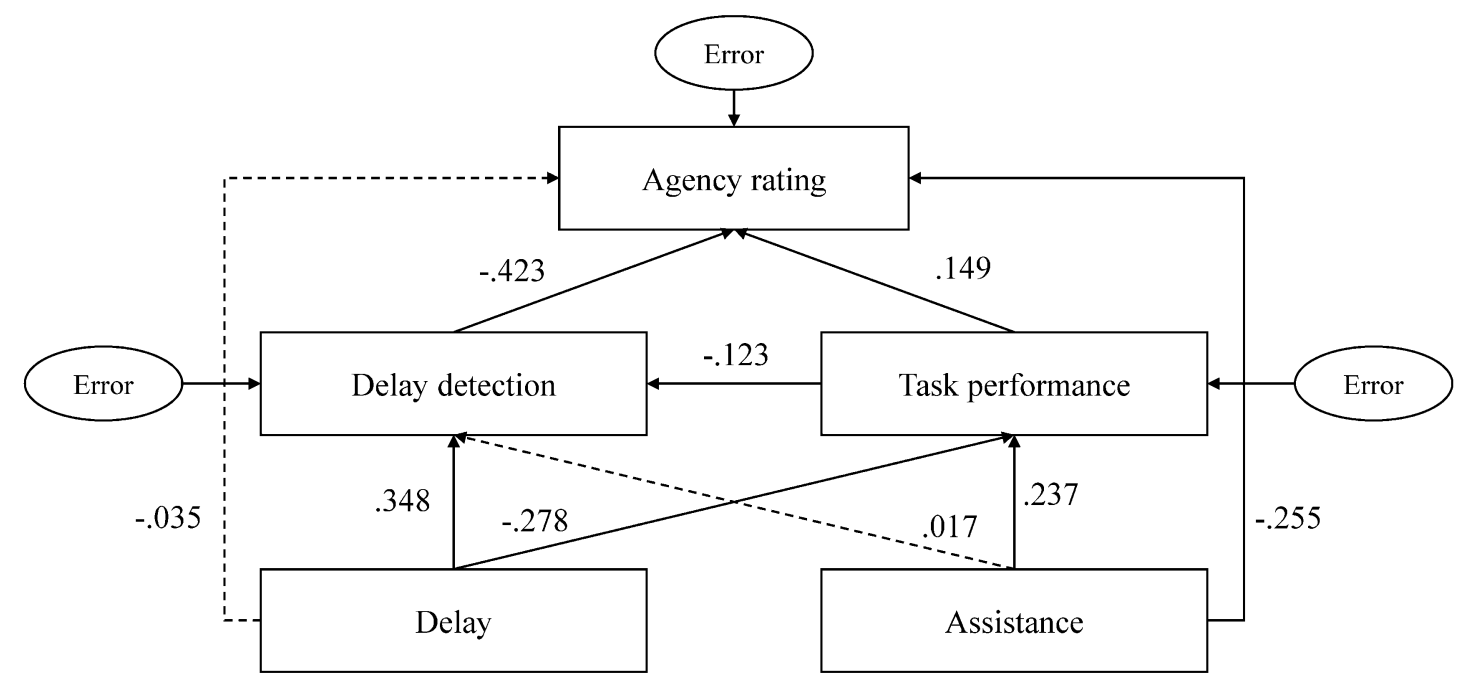

Figure 7. The structural equation model of the sense of agency and its predictors. The paths with significant coefficients are shown as solid lines, and the paths with nonsignificant coefficients are shown as broken lines. The model shows that assistance decreased delay detection by improving task performance, and that less delay detection 
and better task performance significantly contributed to a stronger sense of agency.

\section{Discussion}

The present study examined the influence of performance on action-effect integration in an agency task (i.e., a modified delay detection paradigm). We hypothesized that when task performance is improved, people's action-effect integration would be enhanced, thus resulting in less delay detection for relatively longer delays. We tested this hypothesis in two experiments. In Experiment 1, we examined the delay detection when participants' performance was improved because a proportion of their erroneous commands were not executed. In Experiment 2, we examined delay detection when participants' commands had a specific probability of being randomly cancelled and no feedback on performance was provided. We further compared the features of delay detection between the two experiments.

Our hypothesis was supported by the results for delay detection rates. When participants' task performance was improved through the computer's assistance in Experiment 1, participants detected delays significantly less often in the 480-ms delay condition compared to when no assistance was given, despite a large proportion of participants' commands being ignored. Further, the results from the logistic fittings showed that participants' threshold of delay detection was larger in the assistance 
condition than in the self-control condition, wherein all their commands were executed.

Therefore, improvement of task performance widened the time window of action-effect integration, even when a large proportion of the effects were absent. In contrast, the results of Experiment 2 showed that, when a proportion of participants' commands was ignored, they detected the delays significantly more often. Furthermore, the results of the logistic fitting showed that the delay detection was less precise (i.e., the slopes were gentler) in the disturbed condition than in the self-control condition, although the threshold did not differ. The less precise delay detection might be the result of the moving dot having fewer responses or participants' misidentification of cancelled commands as delayed ones. The hypothesis was further supported by the observed results from Experiment 1. Specifically, not-delayed judgments were associated with better task performance, whereas delayed judgments were associated with poorer task performance.

Delay detection reflects the integration of actions and effects, and is similar to the intentional binding effect. The intentional binding effect is considered an implicit index of the sense of agency (e.g., Bednark, Poonian, Palghat, McFadyen, \& Cunnington, 2015; Moore \& Fletcher, 2012; Moore et al., 2012). A prior study used the delay detection paradigm to measure intentional binding, with the goal of examining the 
underlying processes of sense of agency (Kawabe, Roseboom, \& Nishida, 2013). The authors reported that when separate tones were paired with key presses and visual effects triggered by those key presses, the threshold of delay detection decreased and the sense of agency weakened compared to when synchronized tones were used (Kawabe et al., 2013). Therefore, the grouping of actions and effects appears to reflect an underlying mechanism of the sense of agency. In the present study, we found that, although the assistance led to an increase in the delay detection threshold, it weakened the sense of agency in Experiment 1. This suggests that the integration of actions and effects is only one of multiple cues that contribute to a sense of agency. Further, the results of the multivariate analysis provided detailed information on the relationships between delay detection, task performance, and sense of agency. We specifically found that better integration of action and effect (i.e., less delay detection) was significantly associated with a stronger sense of agency. In other words, the implicit and explicit aspects of the sense of agency were actually positively correlated. This suggests that the lower sense of agency observed in the assisted condition was a direct result participants' commands being ignored via the assistance. Furthermore, the indirect influence of assistance on the sense of agency via delay detection and task performance was positive. Wen et al. (2015b), using a similar task and experimental conditions, reported 
that when the delay in the dot's response was 400 or $700 \mathrm{~ms}$, ignoring erroneous commands significantly improved the sense of agency. Their interpretation of this was that when the delay was long (i.e., over $400 \mathrm{~ms}$ ), performance-based inference had a stronger contribution to sense of agency than did sensory processes (Wen et al., 2015b). In contrast, in our experiments, agency ratings did not differ between the assisted and self-control conditions when the delay was 400 or $480 \mathrm{~ms}$, and were significantly lower in the assisted condition when the delay was less than $400 \mathrm{~ms}$. The results of the multivariate analysis showed that the direct influence of assistance on agency rating was stronger than was the indirect influence via task performance. This indicates that sensory processes had greater weight in determining the sense of agency than did performance-based inferences. This was probably because the weights of performance-based inference and sensory processes varied according to task demand. Specifically, in Wen et al.'s (2015b) study, the participants might have paid more attention to goal achievement and therefore put more weight on performance-based cues when making judgments of agency. In contrast, participants in the present study were instructed to pay attention to the delay in response, and therefore might have put relatively more weight on the sensory cues during agency judgment. In short, we suggest that the weights of the many cues that contribute to a sense of agency might be 
adjusted by external factors.

In conclusion, the present study found that improving task performance

reduced delay detection and widened the time window of action-effect integration.

Furthermore, action-effect integration was strongly associated with explicit judgments of agency, according to the results of the multivariate analysis. Finally, the principle of integration of the multiple cues that contribute to a sense of agency might be adjusted by external factors. However, the threshold and steepness of the delay detection curves were calculated using a relatively small sample because many participants had to be excluded because of a failure of the logistic fitting in the assisted and disturbed conditions. This resulted in rather weak statistical power for this analysis. Future studies should be conducted to further examine the sensory processes underlying the sense of agency in the presence of an external disturbance.

\section{Acknowledgements}

This work was supported by JSPS KAKENHI Grant Number 26120005 and 15K16007, and the research grant from the Precise Measurement Technology Promotion Foundation. 


\section{References}

Barlas, Z., \& Obhi, S. S. (2013). Freedom, choice, and the sense of agency. Frontiers in Human Neuroscience, 7(August), 514. http://doi.org/10.3389/fnhum.2013.00514

Bednark, J. G., Poonian, S. K., Palghat, K., McFadyen, J., \& Cunnington, R. (2015). Identity-specific predictions and implicit measures of agency. Psychology of Consciousness: Theory, Research, and Practice, 2(3), 253-268. http://doi.org/10.1037/cns0000062

Berberian, B., Sarrazin, J.-C., Le Blaye, P., \& Haggard, P. (2012). Automation technology and sense of control: A window on human agency. PLoS ONE, 7(3), e34075. http://doi.org/10.1371/journal.pone.0034075

Binetti, N., Lecce, F., \& Doricchi, F. (2012). Time-dilation and time-contraction in an anisochronous and anisometric visual scenery. Journal of Vision, 12(7), 1-19. http://doi.org/10.1167/12. 7.8

Blakemore, S.-J., Frith, C. D., \& Wolpert, D. M. (1999). Spatio-temporal prediction modulates the perception of self-produced stimuli. Journal of Cognitive Neuroscience, 11(5), 551-559. http://doi.org/10.1162/089892999563607

Blakemore, S.-J., Wolpert, D. M., \& Frith, C. D. (1998). Central cancellation of self-produced tickle sensation. Nature Neuroscience, 1(7), 635-640. 
http://doi.org/doi:10.1038/2870

Blakemore, S.-J., Wolpert, D. M., \& Frith, C. D. (2002). Abnormalities in the awareness of action. Trends in Cognitive Sciences, 6(6), 237-242. http://doi.org/10.1016/S1364-6613(02)01907-1

Demanet, J., Muhle-Karbe, P. S., Lynn, M. T., Blotenberg, I., \& Brass, M. (2013). Power to the will: how exerting physical effort boosts the sense of agency. Cognition, 129(3), 574-578. http://doi.org/10.1016/j.cognition.2013.08.020

Desantis, A., Roussel, C., \& Waszak, F. (2011). On the influence of causal beliefs on the feeling of agency. Consciousness and Cognition, 20(4), 1211-1220. http://doi.org/10.1016/j.concog.2011.02.012

Farrer, C., Valentin, G., \& Hupé, J. M. (2013). The time windows of the sense of agency. Consciousness and Cognition, 22(4), 1431-1441. http://doi.org/10.1016/j.concog.2013.09.010

Franck, N., Farrer, C., Georgieff, N., Marie-Cardine, M., Daléry, J., D’Amato, T., \& Jeannerod, M. (2001). Defective recognition of one's own actions in patients with schizophrenia. The American Journal of Psychiatry, 158(3), 454-459. http://doi.org/10.1176/appi.ajp.158.3.454

Frith, C. D., Blakemore, S.-J., \& Wolpert, D. M. (2000). Explaining the symptoms of 
schizophrenia : Abnormalities in the awareness of action. Brain Research Reviews, 31, 357-363. http://doi.org/10.1016/S0165-0173(99)00052-1

Gallagher, S. (2000). Philosophical conceptions of the self: Implications for cognitive science. Trends in Cognitive Sciences, 4(1), 14-21. http://doi.org/10.1016/S1364-6613(99)01417-5

Haggard, P., Clark, S., \& Kalogeras, J. (2002). Voluntary action and conscious awareness. Nature Neuroscience, 5(4), 382-385. http://doi.org/10.1038/nn827

Haggard, P., \& Cole, J. (2007). Intention, attention and the temporal experience of action. Consciousness and Cognition, 16(2), 211-220. http://doi.org/10.1016/j.concog.2006.07.002

Haggard, P., Martin, F., Taylor-Clarke, M., Jeannerod, M., \& Franck, N. (2003). Awareness of action in schizophrenia. Neuroreport, 14(7), 1081-1085. http://doi.org/10.1097/01.wnr.0000073684.00308.c0

Howard, E. E., Edwards, S. G., \& Bayliss, A. P. (2016). Physical and mental effort disrupts the implicit sense of agency. Cognition, 157, 114-125. http://doi.org/10.1016/j.cognition.2016.08.018

Kawabe, T., Roseboom, W., \& Nishida, S. (2013). The sense of agency is action-effect causality perception based on cross-modal grouping. Proceedings of the Royal 
Society B B $\quad$ Biological Sciences, $\quad$ 280(1763), $\quad$ 1-9.

http://doi.org/10.1098/rspb.2013.0991

Knoblich, G., Stottmeister, F., \& Kircher, T. (2004). Self-monitoring in patients with schizophrenia. Psychological Medicine, 34(8), 1561-1569. http://doi.org/10.1017/S0033291704002454

Koreki, A., Maeda, T., Fukushima, H., Umeda, S., Takahata, K., Okimura, T., ... Kato, M. (2015). Behavioral evidence of delayed prediction signals during agency attribution in patients with schizophrenia. Psychiatry Research, 230(1), 78-83. http://doi.org/10.1016/j.psychres.2015.08.023

Lindner, A., Thier, P., Kircher, T. T. J., Haarmeier, T., \& Leube, D. T. (2005). Disorders of agency in schizophrenia correlate with an inability to compensate for the sensory consequences of actions. Current Biology, 15(12), 1119-1124. http://doi.org/10.1016/j.cub.2005.05.049

Maeda, T., Kato, M., Muramatsu, T., Iwashita, S., Mimura, M., \& Kashima, H. (2012). Aberrant sense of agency in patients with schizophrenia: Forward and backward over-attribution of temporal causality during intentional action. Psychiatry Research, 198(1), 1-6. http://doi.org/10.1016/j.psychres.2011.10.021

Metcalfe, J., Eich, T. S., \& Miele, D. B. (2013). Metacognition of agency: Proximal 
action and distal outcome. Experimental Brain Research, 229(3), 485-496. http://doi.org/10.1007/s00221-012-3371-6

Metcalfe, J., \& Greene, M. J. (2007). Metacognition of agency. Journal of Experimental $\begin{array}{lll}\text { Psychology. } & \text { General, } & \text { 136(2), }\end{array}$ http://doi.org/10.1037/0096-3445.136.2.184

Moore, J. W., \& Fletcher, P. C. (2012). Sense of agency in health and disease: A review of cue integration approaches. Consciousness and Cognition, 21(1), 59-68. http://doi.org/10.1016/j.concog.2011.08.010

Moore, J. W., \& Haggard, P. (2008). Awareness of action: Inference and prediction. Consciousness and Cognition, 17(1), 136-144. http://doi.org/10.1016/j.concog.2006.12.004

Moore, J. W., Middleton, D., Haggard, P., \& Fletcher, P. C. (2012). Exploring implicit and explicit aspects of sense of agency. Consciousness and Cognition, 21(4), 1748-1753. http://doi.org/10.1016/j.concog.2012.10.005

Moore, J. W., Wegner, D. M., \& Haggard, P. (2009). Modulating the sense of agency with external cues. Consciousness and Cognition, 18(4), 1056-1064. http://doi.org/10.1016/j.concog.2009.05.004

Moretto, G., Walsh, E., \& Haggard, P. (2011). Experience of agency and sense of 
responsibility. Consciousness and Cognition, 20(4), 1847-1854. http://doi.org/10.1016/j.concog.2011.08.014

Sato, A., \& Yasuda, A. (2005). Illusion of sense of self-agency: Discrepancy between the predicted and actual sensory consequences of actions modulates the sense of self-agency, but not the sense of self-ownership. Cognition, 94(3), 241-255. http://doi.org/10.1016/j.cognition.2004.04.003

Shimada, S., Qi, Y., \& Hiraki, K. (2010). Detection of visual feedback delay in active and passive self-body movements. Experimental Brain Research, 201(2), 359-364. http://doi.org/10.1007/s00221-009-2028-6

Synofzik, M., Thier, P., Leube, D. T., Schlotterbeck, P., \& Lindner, A. (2010). Misattributions of agency in schizophrenia are based on imprecise predictions about the sensory consequences of one's actions. Brain: A Journal of Neurology, 133, 262-271. http://doi.org/10.1093/brain/awp291

Synofzik, M., Vosgerau, G., \& Newen, A. (2008). Beyond the comparator model: A multifactorial two-step account of agency. Consciousness and Cognition, 17(1), 219-239. http://doi.org/10.1016/j.concog.2007.03.010

Synofzik, M., Vosgerau, G., \& Voss, M. (2013). The experience of agency: An interplay between prediction and postdiction. Frontiers in Psychology, 4(MAR), 1-8. 
http://doi.org/10.3389/fpsyg.2013.00127

Takahata, K., Takahashi, H., Maeda, T., Umeda, S., Suhara, T., Mimura, M., \& Kato, M. (2012). It's not my fault: Postdictive modulation of intentional binding by monetary gains and losses. PLoS ONE, 7(12), e53421. http://doi.org/10.1371/journal.pone.0053421

Vinding, M. C., Pedersen, M. N., \& Overgaard, M. (2013). Unravelling intention: Distal intentions increase the subjective sense of agency. Consciousness and Cognition, 22(3), 810-815. http://doi.org/10.1016/j.concog.2013.05.003

Wen, W., Yamashita, A., \& Asama, H. (2015a). The influence of goals on sense of control. Consciousness and Cognition, 37, 83-90. http://doi.org/doi:10.1016/j.concog.2015.08.012

Wen, W., Yamashita, A., \& Asama, H. (2015b). The sense of agency during continuous action: Performance is more important than action-feedback association. PLoS ONE, 10(4), e0125226. http://doi.org/10.1371/journal.pone.0125226

Wolpert, D. M., \& Ghahramani, Z. (2000). Computational principles of movement neuroscience. $\quad$ Nature Neuroscience, $\quad 3$ (Suppl.), 1212-1217. http://doi.org/10.1038/81497

Yoshie, M., \& Haggard, P. (2013). Negative emotional outcomes attenuate sense of 
agency over voluntary actions. Current Biology, 23(20), 2028-2032. http://doi.org/10.1016/j.cub.2013.08.034

Barlas, Z., \& Obhi, S. S. (2013). Freedom, choice, and the sense of agency. Frontiers in Human Neuroscience, 7(August), 514. http://doi.org/10.3389/fnhum.2013.00514

Bednark, J. G., Poonian, S. K., Palghat, K., McFadyen, J., \& Cunnington, R. (2015). Identity-specific predictions and implicit measures of agency. Psychology of Consciousness: Theory, Research, and Practice, 2(3), 253-268. http://doi.org/10.1037/cns0000062

Berberian, B., Sarrazin, J.-C., Le Blaye, P., \& Haggard, P. (2012). Automation technology and sense of control: A window on human agency. PLoS ONE, 7(3), e34075. http://doi.org/10.1371/journal.pone.0034075

Binetti, N., Lecce, F., \& Doricchi, F. (2012). Time-dilation and time-contraction in an anisochronous and anisometric visual scenery. Journal of Vision, 12(7), 1-19. http://doi.org/10.1167/12. 7.8

Blakemore, S.-J., Frith, C. D., \& Wolpert, D. M. (1999). Spatio-temporal prediction modulates the perception of self-produced stimuli. Journal of Cognitive Neuroscience, 11(5), 551-559. http://doi.org/10.1162/089892999563607 
Blakemore, S.-J., Wolpert, D. M., \& Frith, C. D. (1998). Central cancellation of self-produced tickle sensation. Nature Neuroscience, 1(7), 635-640. http://doi.org/doi:10.1038/2870

Blakemore, S.-J., Wolpert, D. M., \& Frith, C. D. (2002). Abnormalities in the awareness of action. Trends in Cognitive Sciences, 6(6), 237-242. http://doi.org/10.1016/S1364-6613(02)01907-1

Demanet, J., Muhle-Karbe, P. S., Lynn, M. T., Blotenberg, I., \& Brass, M. (2013). Power to the will: how exerting physical effort boosts the sense of agency. Cognition, 129(3), 574-8. http://doi.org/10.1016/j.cognition.2013.08.020

Desantis, A., Roussel, C., \& Waszak, F. (2011). On the influence of causal beliefs on the feeling of agency. Consciousness and Cognition, 20(4), 1211-20. http://doi.org/10.1016/j.concog.2011.02.012

Farrer, C., Valentin, G., \& Hupé, J. M. (2013). The time windows of the sense of agency. Consciousness and 22(4), Cognition, 1431-1441. http://doi.org/10.1016/j.concog.2013.09.010

Franck, N., Farrer, C., Georgieff, N., Marie-Cardine, M., Daléry, J., D’Amato, T., \& Jeannerod, M. (2001). Defective recognition of one's own actions in patients with schizophrenia. The American Journal of Psychiatry, 158(3), 454-459. 
http://doi.org/10.1176/appi.ajp.158.3.454

Frith, C. D., Blakemore, S.-J., \& Wolpert, D. M. (2000). Explaining the symptoms of schizophrenia : Abnormalities in the awareness of action. Brain Research Reviews, 31, 357-363. http://doi.org/10.1016/S0165-0173(99)00052-1

Gallagher, S. (2000). Philosophical conceptions of the self: Implications for cognitive science. Trends in Cognitive Sciences, 4(1), 14-21. http://doi.org/10.1016/S1364-6613(99)01417-5

Haggard, P., Clark, S., \& Kalogeras, J. (2002). Voluntary action and conscious awareness. Nature Neuroscience, 5(4), 382-385. http://doi.org/10.1038/nn827

Haggard, P., \& Cole, J. (2007). Intention, attention and the temporal experience of action. Consciousness and Cognition, 16(2), 211-220. http://doi.org/10.1016/j.concog.2006.07.002

Haggard, P., Martin, F., Taylor-Clarke, M., Jeannerod, M., \& Franck, N. (2003). Awareness of action in schizophrenia. Neuroreport, 14(7), 1081-1085. http://doi.org/10.1097/01.wnr.0000073684.00308.c0

Howard, E. E., Edwards, S. G., \& Bayliss, A. P. (2016). Physical and mental effort disrupts the implicit sense of agency. Cognition, 157, 114-125. http://doi.org/10.1016/j.cognition.2016.08.018 
Kawabe, T., Roseboom, W., \& Nishida, S. (2013). The sense of agency is action-effect causality perception based on cross-modal grouping. Proceedings of the Royal Society B: Biological Sciences, 280(1763). http://doi.org/10.1098/rspb.2013.0991

Knoblich, G., Stottmeister, F., \& Kircher, T. (2004). Self-monitoring in patients with schizophrenia. Psychological Medicine, 34(8), 1561-1569. http://doi.org/10.1017/S0033291704002454

Koreki, A., Maeda, T., Fukushima, H., Umeda, S., Takahata, K., Okimura, T., ... Kato, M. (2015). Behavioral evidence of delayed prediction signals during agency attribution in patients with schizophrenia. Psychiatry Research, 1-6. http://doi.org/10.1016/j.psychres.2015.08.023

Lindner, A., Thier, P., Kircher, T. T. J., Haarmeier, T., \& Leube, D. T. (2005). Disorders of agency in schizophrenia correlate with an inability to compensate for the sensory consequences of actions. Current Biology, 15(12), 1119-24. http://doi.org/10.1016/j.cub.2005.05.049

Maeda, T., Kato, M., Muramatsu, T., Iwashita, S., Mimura, M., \& Kashima, H. (2012). Aberrant sense of agency in patients with schizophrenia: Forward and backward over-attribution of temporal causality during intentional action. Psychiatry Research, 198(1), 1-6. http://doi.org/10.1016/j.psychres.2011.10.021 
Metcalfe, J., Eich, T. S., \& Miele, D. B. (2013). Metacognition of agency: Proximal action and distal outcome. Experimental Brain Research, 229(3), 485-496. http://doi.org/10.1007/s00221-012-3371-6

Metcalfe, J., \& Greene, M. J. (2007). Metacognition of agency. Journal of Experimental $\begin{array}{lll}\text { Psychology. } & \text { General, } & \text { 136(2), }\end{array}$ http://doi.org/10.1037/0096-3445.136.2.184

Moore, J. W., \& Fletcher, P. C. (2012). Sense of agency in health and disease: A review of cue integration approaches. Consciousness and Cognition, 21(1), 59-68. http://doi.org/10.1016/j.concog.2011.08.010

Moore, J. W., \& Haggard, P. (2008). Awareness of action: Inference and prediction. Consciousness and Cognition, 17(1), 136-144. http://doi.org/10.1016/j.concog.2006.12.004

Moore, J. W., Middleton, D., Haggard, P., \& Fletcher, P. C. (2012). Exploring implicit and explicit aspects of sense of agency. Consciousness and Cognition, 21(4), 1748-1753. http://doi.org/10.1016/j.concog.2012.10.005

Moore, J. W., Wegner, D. M., \& Haggard, P. (2009). Modulating the sense of agency with external cues. Consciousness and Cognition, 18(4), 1056-64. http://doi.org/10.1016/j.concog.2009.05.004 
Moretto, G., Walsh, E., \& Haggard, P. (2011). Experience of agency and sense of responsibility. Consciousness and Cognition, 20(4), 1847-1854. http://doi.org/10.1016/j.concog.2011.08.014

Sato, A., \& Yasuda, A. (2005). Illusion of sense of self-agency: Discrepancy between the predicted and actual sensory consequences of actions modulates the sense of self-agency, but not the sense of self-ownership. Cognition, 94(3), 241-255. http://doi.org/10.1016/j.cognition.2004.04.003

Shimada, S., Qi, Y., \& Hiraki, K. (2010). Detection of visual feedback delay in active and passive self-body movements. Experimental Brain Research, 201(2), 359-364. http://doi.org/10.1007/s00221-009-2028-6

Synofzik, M., Thier, P., Leube, D. T., Schlotterbeck, P., \& Lindner, A. (2010). Misattributions of agency in schizophrenia are based on imprecise predictions about the sensory consequences of one's actions. Brain: A Journal of Neurology, 133, 262-271. http://doi.org/10.1093/brain/awp291

Synofzik, M., Vosgerau, G., \& Newen, A. (2008). Beyond the comparator model: A multifactorial two-step account of agency. Consciousness and Cognition, 17(1), 219-239. http://doi.org/10.1016/j.concog.2007.03.010

Synofzik, M., Vosgerau, G., \& Voss, M. (2013). The experience of agency: An interplay 
between prediction and postdiction. Frontiers in Psychology, 4(MAR), 1-8. http://doi.org/10.3389/fpsyg.2013.00127

Takahata, K., Takahashi, H., Maeda, T., Umeda, S., Suhara, T., Mimura, M., \& Kato, M. (2012). It's not my fault: Postdictive modulation of intentional binding by monetary gains and losses. PLoS ONE, 7(12), e53421. http://doi.org/10.1371/journal.pone.0053421

Vinding, M. C., Pedersen, M. N., \& Overgaard, M. (2013). Unravelling intention: Distal intentions increase the subjective sense of agency. Consciousness and Cognition, 22(3), 810-815. http://doi.org/10.1016/j.concog.2013.05.003

Wegner, D. M. (2003). The mind's best trick: How we experience conscious will. Trends in Cognitive Sciences, 7(2), 65-69. http://doi.org/10.1016/S1364-6613(03)00002-0

Wen, W., Yamashita, A., \& Asama, H. (2015a). The influence of goals on sense of control. Consciousness and Cognition, 37, 83-90. http://doi.org/doi:10.1016/j.concog.2015.08.012

Wen, W., Yamashita, A., \& Asama, H. (2015b). The sense of agency during continuous action: Performance is more important than action-feedback association. PLoS ONE, 10(4), e0125226. http://doi.org/10.1371/journal.pone.0125226 
Wolpert, D. M., \& Ghahramani, Z. (2000). Computational principles of movement neuroscience. Nature Neuroscience, $\quad$ 3(Suppl.), 1212-1217. http://doi.org/10.1038/81497

Yoshie, M., \& Haggard, P. (2013). Negative emotional outcomes attenuate sense of agency over voluntary actions. Current Biology, 23(20), 2028-2032. http://doi.org/10.1016/j.cub.2013.08.034 
Figure Caption

Figure 1. The flow of each trial in the experimental task. Participants were instructed to direct a moving dot into its destination as quickly as possible by pressing the left and right arrow keys, which changed the direction in which the dot travelled. After the dot had reached the destination, participants made a two-alternative forced choice regarding whether the dot's response to their key press had been delayed, and then rated their sense of control over the direction in which the dot travelled.

Figure 2. Mean delay detections rates in each condition in Experiment 1 (a) and Experiment 2 (b). Error bars represent the standard errors. Broken lines represent the logistic fitting curves for each controlling mode condition in each experiment.

Note: $* p<.05 ; * * p<.01$.

Figure 3. Mean slopes (a) and 50\% thresholds (b) of the delay detection curves for the self-control and assisted/disturbed conditions in Experiments $1(\mathrm{n}=9)$ and $2(\mathrm{n}=11)$. Error bars represent the standard errors. The slope in the self-control condition of Experiment 2 was steeper than was that in the disturbed condition. On the other hand, the threshold of delay detection was greater in the assisted condition in Experiment 1 than in the self-control condition, but did not differ between the two conditions in Experiment 2. 
Figure 4. Mean agency rating scores in each condition in Experiment 1 (a) and

Experiment 2 (b). Error bars represent the standard errors. The agency ratings in the conditions in which a proportion of participants' commands were ignored (i.e., the assisted and disturbed conditions) were significantly lower than were those in the self-control conditions in both experiments. However, agency ratings in the two longest delay conditions did not differ between the two controlling modes in Experiment 1.

Notes: $* p<.05 ; * * p<.01$.

Figure 5. Mean time taken for the dot to reach in its destination in each condition (a) and mean proportions of ignored key presses in the assisted condition (b) in Experiment 1. Error bars represent the standard errors. The assistance significantly improved task performance by ignoring the participants' erroneous commands.

Note: $* * p<.01$.

Figure 6. Mean time taken for the dot to reach in its destination in the self-control condition of Experiment 1 when participants made judgments of not delayed and delayed. The participants' not-delayed judgments were significantly related with better task performance (i.e., earlier arrivals).

Figure 7. The structural equation model of the sense of agency and its predictors. The paths with significant coefficients are shown as solid lines, and the paths with 
nonsignificant coefficients are shown as broken lines. The model shows that assistance decreased delay detection by improving task performance, and that less delay detection and better task performance significantly contributed to a stronger sense of agency. 